\title{
Early syphilis: serological treatment response to doxycycline/tetracycline versus benzathine penicillin
}

\author{
Jun Li, He-Yi Zheng \\ Department of Dermatology and Venereology, Peking Union Medical College Hospital, Chinese Academy of \\ Medical Sciences and Peking Union Medical College, Beijing, China
}

\begin{abstract}
Introduction: Benzathine penicillin $G$ is the treatment of choice for syphilis, but doxycycline and tetracycline are effective second-line treatments. The objective of this study was to assess the serological response to treatment for early syphilis with benzathine penicillin compared with doxycycline or tetracycline.

Methodology: We examined rapid plasma regain (RPR) serological test results of all first-time early syphilis patients in Peking Union Medical College Hospital between 2000 and 2011, comparing treatment with two doses of penicillin to 14-day course of oral doxycycline (100 mg twice daily) or oral tetracycline (500 mg 4 times a day).

Results: Of the 641 early syphilis cases with available treatment outcome data, $606(94.5 \%)$ received penicillin and $35(5.5 \%)$ received doxycycline/tetracycline. More than half (52.1\%) had secondary syphilis, $13.4 \%$ had primary syphilis, and 34.5\% had early latent syphilis. A statistically similar serological treatment success rate $(\mathrm{p}=0.157)$ was observed in penicillin-treated patients $91.4 \%(554 / 606)$, when compared with patients treated with doxycycline/tetracycline $82.9 \%(29 / 35)$.

Conclusion: Doxycycline/tetracycline had a similar serological treatment success rate when compared to penicillin in the treatment of early syphilis.
\end{abstract}

Key words: doxycycline; tetracycline; penicillin; early syphilis; syphilis; China

J Infect Dev Ctries 2014; 8(2):228-232. doi:10.3855/jidc.3103

(Received 14 September 2012 - Accepted 23 July 2013)

Copyright $\odot 2014 \mathrm{Li}$ et al. This is an open-access article distributed under the Creative Commons Attribution License, which permits unrestricted use, distribution, and reproduction in any medium, provided the original work is properly cited.

\section{Introduction}

Syphilis is a spirochetal infection with multiple manifestations. In recent years, syphilis has reemerged as a significant public health problem in many countries including China. Nationwide surveillance data indicated that the incidence rate of syphilis in China in 1993 was 0.2 cases per 100,000 persons, whereas primary and secondary syphilis alone represented 5.7 cases per 100,000 persons in 2005. The rate of congenital syphilis considerably increased with an average annual rise of $71.9 \%$, from 0.01 cases per 100,000 live births in 1991 to 19.7 cases per 100,000 live births in 2005 [1]. According to nationwide surveillance data, there were 327,433 new cases of syphilis in China in 2009 (24.7 cases per $100,000)[2,3]$.

Controlling syphilis involves the early recognition and adequate treatment of patients with clinical and serological evidence of infection and management of all sexual partners. Benzathine penicillin $G$ has been the treatment of choice for early infectious syphilis (primary, secondary, and early latent syphilis). In the absence of contraindications, doxycycline or tetracycline are second-line treatments considered for patients unable to tolerate penicillin allergies [4]. However, there are limited studies on the use of these second-line agents for early syphilis treatment [5-11]. We conducted a retrospective cohort study to compare the serological response rates of patients with early syphilis treated with penicillin and patients allergic to penicillin treated with doxycycline/tetracycline.

Despite the challenges in the interpretation of serological test results, change in nontreponemal titers is the most widely used criterion for evaluation of the response to syphilis treatment [12-16]. Patients with nontreponemal titers that decline 4-fold or more by 6 months following treatment are regarded as having an appropriate serological response, whereas an increase in titer without reinfection is indicative of treatment failure [4]. 


\section{Methodology}

Study subjects

Demographic, clinical, and laboratory data of 748 patients with syphilis were retrospectively analyzed. Of the 748 early syphilis cases, 385 cases had secondary syphilis, 98 cases had primary syphilis, and 265 cases had early latent syphilis. All syphilitic cases were outpatients who visited the sexually transmitted disease (STD) clinic of Peking Union Medical College Hospital, China, between December 2000 and 2011. All patients were diagnosed with syphilis in different stages according to the national Centers for Disease Control diagnostic standard. According to national guidelines [17], primary syphilis was defined as a clinically compatible case characterized by one or more chancres and inguinal lymphadenopathy, and laboratory confirmation of Treponema pallidum in clinical specimens by rapid plasma reagin serological test (RPR) and particle agglutination assay for antibody to Treponema pallidum (TPPA), and/or FTAAbs; secondary syphilis was defined as a clinically compatible case characterized by maculopapular rash and, in many cases, lymphadenopathy, and laboratory test confirmation for the primary syphilis; early latent syphilis was defined as an asymptomatic case with a possible history of infection supported by reactive RPR and a reactive treponemal test, and normal cerebrospinal fluid Clinicians from the STD of our Institution ask the patient the possible infection time: when initial infection has occurred within the previous 12 months, latent syphilis is classified as early. The study was approved by the ethics committee of the Peking Union Medical College. One hundred and seven patients were excluded because they were HIV positive, nonreactive RPR test at baseline, they had past episodes of syphilis, inadequate follow-up time to determine serological outcome of treatment (patients lost to follow up within 6 months were excluded).

\section{Laboratory testing}

Four $\mathrm{ml}$ of blood was collected from each patient during the first time they visited our STD clinic. Then, the blood was transported to the laboratory where trained laboratory personnel performed RPR and TPPA and/or FTA-Abs (Quality control: Syphilis Serology Proficiency Testing Survey, Laboratory Code Number 990077, Centers for Disease Control and Prevention Atlanta, World Health Organization). Each test was performed by laboratory staff on sera according to manufacturer's instructions. The patient's syphilis stage was assessed based on physical examination and on serology results using the criteria described previously.

\section{Treatment}

According to national guidelines [17], patients with early syphilis were treated with two doses of benzathine penicillin, 2.4 million units intramuscular each, separated by one week. Patients allergic to penicillin were treated with doxycycline, $100 \mathrm{mg}$ orally twice a day for 14 days or tetracycline $500 \mathrm{mg}$ orally, 4 times a day for 14 days. As a routine in our STD clinic, after treatment, all the patients were asked to periodically review their clinical symptoms and serum RPR titers every 3 months. The primary outcome was response to therapy, determined on the basis of changes in RPR titers at 6 months after treatment. Serological treatment success was defined as either negative RPR test results or a $\geq 4$-fold ( 2 dilutions) decrease in titer at 6 months. If rapid plasma reagin test titer was $1: 2$, or $1: 1$ at baseline, a serofast stable serology (i.e., \pm 1 dilution from baseline) at 6 months after treatment initiation was also considered treatment success. Treatment was considered to have failed if none of the above conditions were met, including if the rapid plasma reagin test titer increased from baseline by at least 4 -fold between month 1 and month 6 [4].

\section{Data analysis}

Pearson's chi-squared test was used to compare differences in categorical variables and Student's $t$-test for normally distributed continuous variables. Results were considered statistically significant at $\mathrm{p}<0.05$.

\section{Results}

Of the 641 early syphilis cases with available treatment outcome data, $606 \quad(94.5 \%)$ received penicillin and 35 (5.5\%) received doxycycline/tetracycline. Overall, the mean age of the patients in the study cohort was 35 years of age (ranged between 15 and 80 years of age), subjects were mostly male $(52.6 \%)$. More than half $(52.1 \%)$ had secondary syphilis, $13.4 \%$ had primary syphilis, and $34.5 \%$ had early latent syphilis. There was a similar distribution of patient characteristics in each treatment group (Table 1$)$. A statistically similar $(\mathrm{p}=0.157)$ serological treatment success rate was observed in $91.4 \%(554 / 606)$ of penicillin-treated patients when compared with $82.9 \%(29 / 35)$ of patients treated with doxycycline/tetracycline. 
Table 1. Baseline characteristics of early syphilis patients

\begin{tabular}{|c|c|c|c|c|c|}
\hline & \multicolumn{2}{|c|}{$\begin{array}{c}\text { Benzathine penicillin } G \\
(n=606)\end{array}$} & \multicolumn{2}{|c|}{$\begin{array}{l}\text { Doxycycline or tetracycline } \\
\qquad(\mathrm{n}=35)\end{array}$} & \multirow{2}{*}{ P Value } \\
\hline & $\mathrm{n}$ & $\%$ & $\mathrm{n}$ & $\%$ & \\
\hline Age (years) & & & & & 0.329 \\
\hline$\leq 26$ & 138 & 22.8 & 10 & 28.6 & \\
\hline $27-33$ & 176 & 29.0 & 11 & 31.4 & \\
\hline $34-40$ & 123 & 20.3 & 6 & 17.1 & \\
\hline$\geq 41$ & 169 & 27.9 & 8 & 22.9 & \\
\hline Sex & & & & & 0.125 \\
\hline Male & 323 & 53.3 & 14 & 40.0 & \\
\hline Female & 283 & 46.7 & 21 & 60.0 & \\
\hline Ethnicity & & & & & 0.688 \\
\hline Han & 417 & 95.4 & 21 & 91.3 & \\
\hline Minority & 20 & 4.6 & 2 & 8.70 & \\
\hline Sexual orientation & & & & & 1.000 \\
\hline Heterosexual & 563 & 98.8 & 34 & 100.0 & \\
\hline Homosexual & 7 & 1.2 & 0 & 0 & \\
\hline Condom use & & & & & 0.295 \\
\hline Consistent use & 131 & 33.0 & 6 & 23.1 & \\
\hline Inconsistent or never use & 266 & 67.0 & 20 & 76.9 & \\
\hline No. of sex partners & & & & & 0.291 \\
\hline $0-1$ & 225 & 58.6 & 13 & 65.0 & \\
\hline $2-3$ & 105 & 27.3 & 6 & 30.0 & \\
\hline $4-5$ & 36 & 9.4 & 1 & 5.0 & \\
\hline$>5$ & 18 & 4.7 & 0 & 0 & \\
\hline Initial RPR titer & & & & & 0.101 \\
\hline$\leq 1: 4$ & 94 & 15.5 & 10 & 28.6 & \\
\hline $1: 8$ & 48 & 7.9 & 5 & 14.3 & \\
\hline $1: 16$ & 106 & 17.5 & 5 & 14.3 & \\
\hline $1: 32$ & 173 & 28.5 & 5 & 14.3 & \\
\hline$\geq 1: 64$ & 185 & 30.5 & 10 & 28.6 & \\
\hline Stage & & & & & 0.336 \\
\hline Primary & 80 & 13.2 & 6 & 17.1 & \\
\hline Secondary & 320 & 52.8 & 14 & 40.0 & \\
\hline Early latent & 206 & 34.0 & 15 & 42.9 & \\
\hline Coinfection with other STDs* & & & & & 0.488 \\
\hline No & 535 & 88.3 & 29 & 82.9 & \\
\hline Yes & 71 & 11.7 & 6 & 17.1 & \\
\hline
\end{tabular}

*STDs, Sexually Transmitted Diseases 


\section{Discussion}

Doxycycline is a tetracycline derivative with better oral bioavailability, convenient twice a day dosing, and fewer gastrointestinal side effects. Doxycycline at a dosage of $100 \mathrm{mg}$ every 12 hours is pharmacologically equivalent to tetracycline at $500 \mathrm{mg}$ every 6 hours [18]. The mean inhibitory and bactericidal concentrations against treponemes are similar for tetracycline and doxycycline [19-20]. The major advantages of Benzathine penicillin treatment are its safety, effectiveness, and the favorable adherence to the weekly dosing schedule of 1 to 3 weeks [21]. Disadvantages of this regimen include the cost, pain associated with intramuscular injection, and the incidence of penicillin allergy in some patients. Several characteristics of doxycycline or tetracycline make them attractive alternatives to penicillin, including their oral route of administration and their pharmacologic and pharmacokinetic properties.

One of the key findings of our study is that serological treatment success (in penicillin treated patients the rate was $91.4 \%$ and doxycycline/tetracycline treated patients it was $82.6 \%$ ) was not as high as in previously published reports. A study by Ghanem et al [8] using a retrospective chart review showed good response to doxycycline among patients with early syphilis from two STD clinics in Baltimore. In that study, serological treatment success was noted among 69 of $73(94.5 \%)$ patients treated with penicillin, while $100 \%$ among 34 patients treated with doxycycline. Another study from Canada by Wong et al [5] used a retrospective study to assess the serological response to treatment of primary syphilis with benzathine penicillin compared with doxycycline or tetracycline. In that study, of the total 445 primary syphilis cases with available treatment outcome data, $420(94.4 \%)$ received penicillin and 25 (5.6\%) received doxycycline/tetracycline. The serological treatment success rate was $97.4 \%$ in the penicillin group (409/420) and $100 \%$ in the doxycycline/tetracycline group (25/25), and not significantly different. However, In another example in Tanzania, Riedner et al. used a similar 4-fold decrease in rapid plasma reagin test titer to define serological success and found serological success rates of only approximately $80 \%$ with penicillin at 6 months [22]. The broad range of treatment success may be related to variations in formulations and dosing of penicillin, in addition to the different methods adopted by each study. Overall, our data, along with these reports, provide a basis for the use of doxycycline as an alternative therapeutic option in the treatment of early syphilis.

\section{Aknowledgements}

Young scientific research fund of Peking Union Medical College Hospital

\section{References}

1. Chen ZQ, Zhang GC, Gong XD, Lin C, Gao X, Liang GJ (2007) Syphilis in China: results of a national surveillance programme. Lancet 369: 132-138.

2. 102 NCSTD (2011). Epidemiologic reports of syphilis and gonorrhea case reports in China. Available: http:// www.ncstdc.org/zxgl-detail/zxgl-xxjl.htm Last accessed 11 May 2011.

3. Joseph D Tucker, Yue-Ping Yin, Baoxi Wang, Xiang-Sheng Chen, Myron S Cohen (2011) An expanding syphilis epidemic in China: epidemiology, behavioural risk and control strategies with a focus on low-tier female sex workers and men who have sex with men. Sex Transm Infect 87 Suppl 2: ii16-8.

4. Centers for Disease Control and Prevention (2010) Sexually transmitted diseases treatment guidelines, 2010. Morb Mort Wkly Rep 58: 26-34.

5. Tom Wong, Ameeta E, Prithwish De(2008) Primary Syphilis: Serological Treatment Response to Doxycycline/ Tetracycline versus Benzathine Penicillin. The American Journal of Medicine 121: 903-908.

6. Psomas KC, Brun M, Causse A, Atoui N, Reynes J, Le Moing V(2012) Efficacy of ceftriaxone and doxycycline in the treatment of early syphilis. Med Mal Infect 42: 15-19.

7. Onoda Y (1979) Therapeutic effect of oral doxycycline on syphilis. Br J Vener Dis 55: 110-115.

8. Ghanem KG, Erbelding EJ, Cheng WW, Rompalo AM (2006) Doxycycline compared with benzathine penicillin for the treatment of early syphilis. Clin Infect Dis 42: e45-e49.

9. Cunha BA, Sibley CM, Ristuccia AM (1982) Doxycycline. Ther Drug Monit 4: 115-135.

10. Zenilman JM, Rand S, Barditch P, Rompalo AM (1993) Asymptomatic neurosyphilis after doxycycline therapy for early latent syphilis. Sex Transm Dis 20: 346-347.

11. Harshan V, Jayakumar W (1982) Doxycycline in early syphilis: a long term follow up.Indian J Dermatol 27: 119124.

12. Owusu-Edusei K Jr, Koski KA, Ballard RC (2011) The tale of two serologic tests to screen for syphilis--treponemal and nontreponemal: does the order matter? Sex Transm Dis 38: 448-456.

13. Fiumara NJ (1980) Treatment of primary and secondary syphilis. Serological response. JAMA 243: 2500-2502.

14. Brown ST, Zaidi A, Larsen SA, Reynolds GH (1985) Serological response to syphilis treatment. A new analysis of old data. JAMA 253: 1296-1299.

15. Larsen SA, Steiner BM, Rudolph AH (1995) Laboratory diagnosis and interpretation of tests for syphilis. Clin Microbiol Rev 8: 1-21.

16. Romanowski B, Sutherland R, Fick GH, Mooney D, Love EJ (1991) Serologic response to treatment of infectious syphilis. Ann Intern Med 114: 1005-1009. 
17. SBTS/MOH (1996) National standard of the People's Republic of China: diagnostic criteria and management of syphilis (GB 15974-1995). Beijing: Standards Press of China.

18. Standiford H.C (2005)Tetracyclines and chloramphenicol In: G.L. Mandell, R.G. Douglas, J.E. Bennett (Eds.), Priniciples and Practice of Infectious Diseases (6th edition), Elsevier Churchill Livingstone, Philadelphia, PA 356-373.

19. Abramson IJ, Smibert RM (1971) Smibert Inhibition of growth of treponemes by antimicrobial agents. Br J Vener Dis 47: 407-412.

20. Abramson IJ, Smibert RM (1971) Smibert Bactericidal activity of antimicrobial agents for treponemes. Br J Vener Dis 47: 413-418.

21. Kaplan EL (2012) Benzathine penicillin G: a documentably important antibiotic in need of a tune-up? Pediatr Infect Dis J 31: 726-8.
22. Riedner G, Rusizoka M, Todd J, Maboko L, Hoelscher M, Mmbando D, Samky E, Lyamuya E, Mabey D, Grosskurth H, Hayes R (2005) Single-dose azithromycin versus penicillin $\mathrm{G}$ benzathine for the treatment of early syphilis. $\mathrm{N}$ Engl J Med 353: 1236-1244.

\section{Corresponding author}

He-Yi Zheng, MD.

Department of Dermatology and Venereology, Peking Union Medical College Hospital, Chinese Academy of Medical Sciences and Peking Union Medical College, Beijing 100730, China.

Phone: 86-010-69156392;

Fax: 86-010-69156392;

E-mail: zhenghy62@hotmail.com

Conflict of interests: No conflict of interests is declared. 